\title{
Expression analysis of intercellular adhesion molecule-2 (ICAM-2) in the context of classical cardiovascular risk factors in acute coronary syndrome patients
}

\author{
Joanna Głogowska-Ligus', Józefa Dąbek², Elżbieta Zych-Twardowska³ , Magdalena Tkacz ${ }^{4}$
}

1Department of Epidemiology, Medical University of Silesia, Katowice, Poland 2Department of Cardiology, Medical University of Silesia, Katowice, Poland 3Department of Neurology, Medical University of Silesia, Katowice, Poland 4 Institute of Computer Science, University of Silesia, Katowice, Poland

Submitted: 8 June 2011

Accepted: 29 January 2012

Arch Med Sci 2013; 9, 6: 1035-1039

DOI: 10.5114/aoms.2012.28808

Copyright $\odot 2013$ Termedia \& Banach

\begin{abstract}
Introduction: Cardiopulmonary diseases are the most common cause of hospitalization and death. Often the basic problem is endothelial dysfunction leading to elevated expression of adhesion proteins as well as increased adhesion and aggregation of blood cells. The goal of the study was to assess expression level of intercellular adhesive molecule-2 (ICAM-2) in patients with acute coronary syndrome (ACS).

Material and methods: The obtained data were analysed in the context of the occurrence of classical cardiovascular risk factors. The two studied groups consisted of 60 ACS patients and 20 healthy individuals who both were qualified based on electrocardiography (ECG), transthoracic echocardiography and biochemical tests. The ACS patients additionally had coronary angiography performed. The number of ICAM-2 gene mRNA molecules was evaluated on the basis of QRT-PCR reaction kinetics. To compare the results the Mann-Whitney $U$ test was used. Results were judged statistically significant if $p<0.05$.

Results: Analysis of the results showed a significantly higher number of ICAM-2 gene mRNA copies in ACS patients compared to healthy subjects (140920 \pm 105207 and $15023 \pm 14325$, respectively). Furthermore, our results indicate a correlation between obesity $(p=0.012)$ and positive burdening family history $(p=0.041)$ and increased ICAM-2 levels in patients with ACS.

Conclusions: Increased ICAM-2 gene expression in ACS patients is probably symptomatic of endothelium dysfunction and may be responsible for intensified adhesion and aggregation processes as well as for appearance of acute coronary syndrome. These results indicate a correlation between obesity and burdening family history on the one hand, and increased ICAM-2 levels in patients with $\mathrm{ACS}$, on the other.
\end{abstract}

Key words: adhesion molecule, aggregation, obesity.

\section{Introduction}

Cardiovascular diseases are among the most frequent causes of hospitalization and death. Scientific knowledge underlying coronary atherosclerotic complications, notably acute cardiac syndrome, has improved a great deal in recent years. The causes are believed to include endothelial dysfunction, inflammation and increased permeability of vessel wall and

\section{Corresponding author:}

Joanna Głogowska-Ligus MD, PhD Department of Epidemiology Medical University of Silesia 18 Piekarska St 41-902 Bytom, Poland Phone: +48 323976531 E-mail: jglogowska@sum.edu.pl 
neurohormonally mediated endothelial reactions. Such processes favour interactions of blood-borne elements with the vessel wall, especially molecules that participate in adhesion, aggregation and the blood clotting cascade. Aggravated ischaemic heart disease and myocardial infarction can be caused by several factors [1].

In the majority of cases the infarction is caused by destabilized blood vessel plaque and formation of a clot which totally or partially occludes the blood vessel lumen [2].

Many studies have demonstrated the link between cardiovascular risk and level of fibrinogen. It is believed that this protein (a thrombin substrate) is involved in the final stages of the clotting process. Fibrinogen binds platelets causing their aggregation, modulates endothelial functioning and affects plasminogen binding. In addition, fibrinogen is believed to be an acute phase protein [3]

Endothelial dysfunction and its impaired anticoagulant function also lead to elevated expression of various cell adhesion molecules (intercellular adhesion molecules [ICAM], vascular cell adhesion molecule [VCAM-1], selectins and integrins) on the surface of the initial atherosclerotic lesion [4].

Leukocytes and cells originating from the blood vessel wall secrete proinflammatory cytokines and growth factors which further increase leukocyte recruitment as well as causing migration and proliferation of smooth muscle cells. During plaque progression, the inflammatory mediators trigger expression of tissue factor, a protein with potential procoagulant action, as well as expression of proteinases responsible for matrix breakdown, thereby favouring transition from a stable to an unstable plaque. Plaque rupture at the site of its cover allows circulating clotting factors easy access to the thrombogenic lipid core containing the tissue factor. Thrombus formation at the site of plaque rupture is dependent on the local equilibrium between proclotting/fibrinolytic factors and may lead to cardiac infarction [5].

Expression of intercellular adhesion molecule-2 (ICAM-2) was examined in mononuclear peripheral blood cells from ACS patients. The obtained data were analysed in the context of the occurrence of classical cardiovascular risk factors.

\section{Material and methods}

The research project was designed according to Declaration of Helsinki-based GCP guidelines and was positively endorsed by the Bioethics Commission of the Medical University of Silesia in Katowice on 21 December 2004 (resolution NN-6501-223/I/04).

Prospective study subjects were included in the investigation when voluntary written consent to participate had been obtained.

The experimental group was set up based on specific inclusion and exclusion criteria. The fol- lowing study inclusion criteria were established: a) age above 18 years, b) conscious consent, c) firsttime cardiac incident, i.e. lack of previous treatment for coronary disease), d) typical coronary chest pain lasting less than $12 \mathrm{~h}$, e) ECG changes in ST-T segment and $T$ wave, or block of left atrioventricular bundle branch.

The exclusion criteria included: a) no consent to participate, b) acute or chronic inflammatory disease, or autoimmune disease, c) renal insufficiency, d) severe hypertension, e) advanced circulatory failure, f) chest pain of non-cardiac origin.

ECG and cardiac Echo were performed upon clinic admittance of all subjects participating in the study, besides urgent coronarography and basic laboratory tests. Concentration of cardiac necrosis markers was also determined in the subjects.

The control group included healthy individuals (none of them was ever treated before for cardiology-related problems), who reported to the emergency department with chest pain such as neurosis or indigestion. They were included in the control group based on interview, physical examination and results of laboratory tests (blood morphology/blood smear, erythrocyte sedimentation rate [ESR], lipid profile, serum glucose concentration, creatinine, electrolytes) and no changes in coronary vessel angiography or 64-row multidetector computed tomography picture, the latter assessing coronary artery calcification (calcium score). All study participants were domiciled in the Upper Silesia region.

As material for study, RNA isolated from peripheral blood mononuclear cells was used. Transcriptional activity of the examined gene was assessed using a commercially available kit (TaqMan Gene Expression Assays, Applied Biosystems, Foster City, CA, USA). The number of ICAM-2 mRNA molecules was determined based on QRT-PCR reaction kinetics using the $A B I$ PRISM $^{\mathrm{TM}} 7000$ sequence detection system (Applied Biosystems) and a kit containing fluorescent dye (ROX QuantiTect Probe RT-PCR, Quiagen, Germany). QRT-PCR was performed in one step using a reaction mix containing $25 \mu \mathrm{l} 2 \times$ QuantiTect Probe RT-PCR Master Mix (HotStarTaq DNA Polymerase, QuantiTect Probe RT-PCR buffer containing Tris- $\mathrm{HCl}$, $\mathrm{KCl},\left(\mathrm{NH}_{4}\right)_{2} \mathrm{SO}_{4}, 8 \mathrm{mM} \mathrm{MgCl}, \mathrm{pH}=8.7$, dNTP mix, ROX reference dye) and $0.5 \mu \mathrm{l}$ QuantiTect RT Mix (Omniscript Reverse Transcriptase, Sensiscript Reverse Transcriptase in commercially available concentrations) and $1 \mu \mathrm{l}$ of starters and T Gene Expression Assay probes (Applied Biosystems), RNA template and apyrogenic water. Together with the examined gene, commercially available DNA standards ( $\beta$-actin, GAPDH, Applied Biosystems) were amplified. Reverse transcription reaction was performed at $50^{\circ} \mathrm{C}$ for 30 min. Following initial activation of HotStarTaq DNA Polymerase at $95^{\circ} \mathrm{C}$ for $15 \mathrm{~min}$, a two-stage reaction was carried out with denaturation at $94^{\circ} \mathrm{C}$ for $15 \mathrm{~s}$ 
and starter ligation at $60^{\circ} \mathrm{C}$ for $60 \mathrm{~s}$. Final elongation of amplification products was achieved at $72^{\circ} \mathrm{C}$ for $10 \mathrm{~min}$.

\section{Statistical analysis}

The expression level of the examined gene was inferred on the basis of the number of obtained mRNA copies per $1 \mu \mathrm{g}$ of total RNA. Statistical significance of ICAM-2 expression values obtained for ACS patients and for controls was measured using Mann-Whitney $U$ test. The results were judged significant if $p<0.05$. Transcriptional activity of ICAM-2 in the ACS group, taking into account the chosen risk factors, was assessed using the number of mRNA copies per $1 \mu \mathrm{g}$ of total RNA. The analysis was carried out by singling out the results obtained with particular patients with respect to such risk factors as arterial hypertension, diabetes, lower limb atherosclerosis, tobacco smoking, obesity and burdening family history.

\section{Results}

Subjects eligible for study participation were patients ( $n=60$ ) with acute cardiac syndrome who were admitted to the clinic. Twenty healthy volunteers served as the control group.

The mean age was 53 years (38-69 years) in the ACS patient group and 49 years (40-65 years) in the control group. Subjects who participated in the study included 15 females and 45 males with ACS and 10 females and 10 males in the control group.

Analysis of the results demonstrated a significantly higher number of ICAM-2 gene copies in

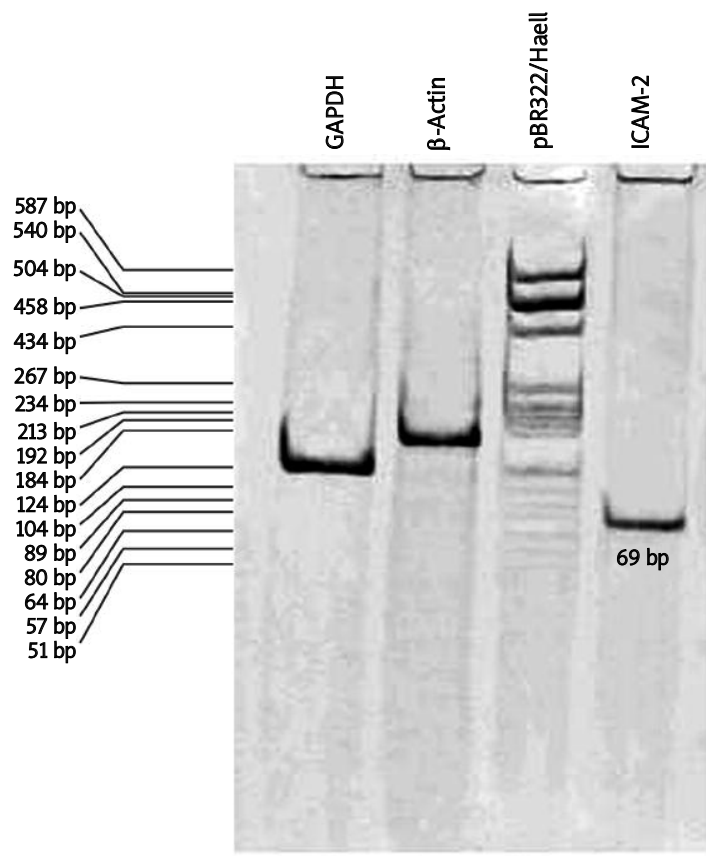

Figure 1. Polyacrylamide gel electropherogram of amplification products
Table I. Number of ICAM-2 mRNA copies per $1 \mu \mathrm{g}$ of total RNA in ACS patients and in control group

\begin{tabular}{|llc|}
\hline Variable & & ICAM-2 \\
\hline Control group $(n=20)$ & Average & 15023 \\
\cline { 2 - 3 } & \multicolumn{1}{l}{ Standard deviation } & 14325 \\
\cline { 2 - 3 } & Median & 9875 \\
\hline ACS group $(n=60)$ & Average & 140920 \\
\cline { 2 - 3 } & Standard deviation & 105207 \\
\cline { 2 - 3 } & Median & 106261 \\
\hline $\begin{array}{l}\text { Level of statistical significance } \\
\text { (Mann-Whitney } U \text { test) }\end{array}$ & $p<0.001$ \\
\hline
\end{tabular}

samples from ACS patients, as compared to samples from the control group. The numbers were $140920 \pm 105207$ and $15023 \pm 14325$, respectively (Table I).

The results obtained were confirmed by electrophoretically separating the amplification products using a polyacrylamide gel (Figure 1).

Based on QRT-PCR reaction kinetics a correlation graph was generated for ICAM- 2 and $\beta$-actin values in the two studied groups. For better visualization the values were lined up in ascending order (Figure 2).

Analysis of the investigated transcriptional activity of ICAM-2 adhesion molecule and the occurrence of classic risk factors in cardiovascular diseases revealed a statistically significant difference for obese subjects with burdening family history (Table II).

\section{Discussion}

Atherosclerosis is a multifocal chronic inflammatory process affecting mainly large and medium arteries. It begins to develop in early stages of life and progresses with age. Initiation of plaque formation starts with endothelial dysfunction when molecules promoting migration and adhesion of proinflammatory cells appear. At these early stages of plaque development, $\mathrm{T}$ lymphocytes and macropha-

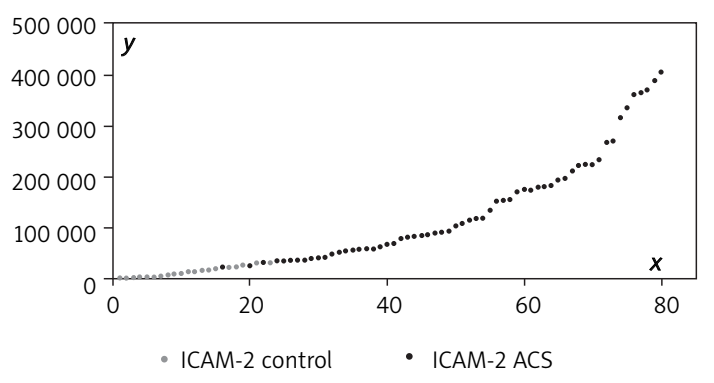

Figure 2. Statistical significance of ICAM-2 gene expression values of persons from control group and from ACS group (native spaker do not understand) $X$ is a number of consecutive value after line-up of results. $Y$ is the number of mRNA copies per $1 \mu \mathrm{g}$ of total RNA 
Table II. Numbers of mRNA copies for ICAM-2 gene in connection with classic risk factors in ACS

\begin{tabular}{|c|c|c|c|c|c|}
\hline Parameter & Occurrence & Average & Median & $\begin{array}{l}\text { Standard } \\
\text { deviation }\end{array}$ & $\begin{array}{l}\text { Level of significance } \\
\text { (Mann-Whitney } U \text { test) }\end{array}$ \\
\hline \multirow[t]{2}{*}{ Arterial hypertension } & Yes & 339489 & 143824 & 1003026 & \multirow[t]{2}{*}{$p=0.117$} \\
\hline & No & 1781512 & 70273 & 278717 & \\
\hline \multirow[t]{2}{*}{ Diabetes } & Yes & 200738 & 196847 & 197799 & \multirow[t]{2}{*}{$p=0.602$} \\
\hline & No & 264101 & 104165 & 765508 & \\
\hline \multirow[t]{2}{*}{ Lower limb atherosclerosis } & Yes & 79369 & 44247 & 76750 & \multirow[t]{2}{*}{$p=0.173$} \\
\hline & No & 271638 & 111874 & 758747 & \\
\hline \multirow[t]{2}{*}{ Tobacco smoking } & Yes & 161607 & 98604 & 185555 & \multirow[t]{2}{*}{$p=0.559$} \\
\hline & No & 426735 & 113711 & 1186546 & \\
\hline \multirow[t]{2}{*}{ Obesity } & Yes & 452322 & 270346 & 456579 & \multirow[t]{2}{*}{$p=0.012$} \\
\hline & No & 241229 & 86361 & 754995 & \\
\hline \multirow[t]{2}{*}{ Burdening family history } & Yes & 96508 & 65986 & 88076 & \multirow[t]{2}{*}{$p=0.041$} \\
\hline & No & 334038 & 153017 & 879586 & \\
\hline
\end{tabular}

ges infiltrate the subendothelial layer, and this testifies to the activation of the immune system. Our study has demonstrated elevated expression of adhesion molecule ICAM-2 in ACS patients, as compared to controls. These results corroborate our earlier findings obtained using oligonucleotide microarrays and stress the role of ICAM- 2 in cardiovascular diseases [6]. There are few published data concerning involvement of ICAM-2 in coronary disease. It is known, though, that this molecule, together with ICAM-1, takes part in lymphocyte recirculation, immune response, NK-cell mediated clearance and surveillance processes. Most likely, increased expression of the ICAM-2 gene is linked to elevated secretion of chemokines, leukocyte adhesion, increased permeability of the cell layer, elevated cytokine synthesis as well as proliferation and migration of smooth muscle cells. The ICAM- 1 and ICAM-2 molecules are expressed on the endothelial cell surface only in small amounts and their expression is stimulated by interferon- $\gamma$, interleukin-1 (IL-1), tumour necrosis factor $\alpha$ (TNF- $\alpha$ ) and oxidized cholesterol (ox-LDL). The ICAM-1 and ICAM-2 ligands include glycoprotein from the $\beta_{2}$-integrin family, lymphocyte function antigen-1 (LFA-1) and leukocyte $\alpha_{M} \beta_{2}$ integrin (Mac-1) present on the surface of neutrophils and monocytes [7]. Circadian variability of serum concentration of adhesion molecules was found; Pselectin was elevated during evening hours, which is explained by its decreased binding to cell membrane [8], whereas no such circadian fluctuation was observed in the case of E-selectin and ICAM-1 concentration. Currently, studies are underway aimed at elucidating the mechanism of adhesion molecules' expression regulation. It has been shown, for example, that actin cytoskeleton is involved in modulating ICAM1 expression in endothelial cells through its destabilization and prevention of asymmetric dimethyl- arginine (ADMA)-induced NF- $\mathrm{B}$ B activation. This hypothesis has been confirmed in studies involving ADMA-treated human umbilical vein endothelial cell (HUVEC) cultures [9]. Inhibited expression of ICAM-1 can also result from treating cells with ganciclovir. It cannot be excluded, though, that the antiproliferative effect can result from drug cytotoxicity [10].

There have been several reports in the literature exploring the relationship between transcriptional activity of genes responsible for expression of adhesion molecules and classical risk factors in cardiovascular diseases. The most frequently investigated factors have been aortal hypertension, tobacco smoking, diabetes and obesity [11-13]. The study of Jin et al. [14] suggested elevated expression of ICAM1 molecules in patients suffering from type- 2 diabetes. In our analysis, no statistically significant difference was noted between the level of ICAM-2 molecule expression and diabetes occurrence. No correlation could be found between the expression of ICAM-2 and the smoker/non-smoker status of subjects from the studied group of patients with ACS, although the effect of this factor on the expression of various genes has long been recognized $[15,16]$. Similarly, no differences were observed concerning expression of the investigated gene in dependence of the so-called non-modifiable risk factors (such as age and sex). It is worth stressing that a statistically significant difference in expression of the ICAM-2 gene was observed in obese patients with ACS. Similar results concerning expression of adhesion molecules and pro-inflammatory genes in atherosclerotic patients were obtained by Orea Soler et al. [17]. These researchers noticed the effect of body mass loss on the changes in expression of these genes. The next statistically significant difference stressing the role played by adhesion molecules in atherosclerotic processes was 
observed in persons with burdening family history [11]. The ICAM-2 molecule expression investigated by us also revealed statistically significant differences depending on burdening family history.

Increased ICAM-2 gene expression seen in patients with myocardial infarction may be responsible for processes leading to occlusion of coronary vessels and to thrombosis. Further studies on the role of ICAM-2 thus seem warranted.

In conclusion, increased ICAM-2 gene expression in ACS patients is probably symptomatic of endothelium dysfunction and may be responsible for intensified adhesion and aggregation processes as well as for appearance of acute coronary syndrome. These results indicate a correlation between obesity and burdening family history on the one hand, and increased ICAM-2 levels in patients with ACS, on the other.

\section{Acknowledgments}

The study was conducted after obtaining written consent from the local Bioethics Commission. The project received a positive opinion from the commission, which issued a relevant resolution (NN-6501-223/I/04).

Molecular work was performed in the Department of Molecular Biology, School of Pharmacy and Division of Laboratory Medicine, Medical University of Silesia in Katowice.

\section{References}

1. Mallika V, Goswami B, Rajappa M. Atherosclerosis pathophysiology and the role of novel risk factors: a clinicobiochemical perspective. Angiology 2007; 58: 513-22.

2. Głogowska-Ligus J, Dabek J, Szota J, Wilczok T, Mazurek U. Gene of platelet/endothelial cell adhesion molecule 1 expression profile in patients with acute coronary syndrome and in healthy subjects performed in peripheral blood mononuclear cells using quantitative QRT-PCR reaction [Polish]. Pol Merkur Lekarski 2009; 26: 9-13.

3. Yan RT, Fernandes V, Yan AT, et al. Fibrinogen and left ventricular myocardial systolic function: The Multi-Ethnic Study of Atherosclerosis (MESA). Am Heart J 2010; 160: 479-86.

4. Hillis GS, Terregino C, Taggart P, et al Soluble intercellular adhesion molecule- 1 as a predictor of early adverse events in patients with chest pain compatible with myocardial ischemia. Ann Emerg Med 2001; 38: 223-8.

5. Golino P, Crea F, Willerson JT. How to study the effects of platelet aggregation and thrombosis on coronary vasomotion and their clinical relevance. Ital Heart J 2002; 3: 220-5.

6. Dąbek J, Głogowska-Ligus J, Szota J. Oligonucleotide microarray and QRT-PCR study of adhesion protein gene expression in acute coronary syndrome patients. Infalmmation 2010; 33: 398-407.

7. Hermand P, Huet M, Callebaut I, et al. Binding sites of leukocyte beta 2 integrins (LFA-1, Mac-1) on the human ICAM-4/LW blood group protein. J Biol Chem 2000; 275: 26002-10.

8. Osmancik P, Kvasnicka J, Widimsky P, Tarnok A. Diurnal variation of soluble E- and P-selectin, and intercellular adhesion molecule-1 in patients with and without coronary artery disease. Cardiology 2004; 102: 194-9.

9. Wei-Kang G, Dong-Liang Z, Xin-Xin W, et al. Actin cytoskeleton modulates ADMA-induced NF-kappaB nuclear translocation and ICAM-1 expression in endothelial cells. Med Sci Monit 2011; 17: BR242-7.

10. Voisard R, Münder U, von Müller L, Baur R, Hombach V. Direct inhibitory effects of Ganciclovir on ICAM-1 expression and proliferation in human coronary vascular cells (SI/MPL-ratio: >1). Med Sci Monit 2011; 17: PI1-6.

11. Bencze J, Kiss RG, Toth-Zsamboki E, et al. Inverse correlation between coronary blood flow velocity and SICAM1 level observed in ischemic heart disease patients. Atherosclerosis 2006; 188: 142-9.

12. Loucks EB, Pilote L, Lynch JW, et al. Life course socioeconomic position is associated with inflammatory markers: the Framingham Offspring Study. Soc Sci Med 2010; 71: 187-95.

13. Nguyen QM, Srinivasan SR, Xu JH, Chen W, Berenson GS. Distribution and cardiovascular risk correlates of plasma soluble intercellular adhesion molecule-1 levels in asymptomatic young adults from a biracial community: the Bogalusa Heart Study. Ann Epidemiol 2010; 20: 53-9.

14. Jin C, Lu L, Zhang RY, et al. Association of serum glycated albumin, C-reactive protein and ICAM-1 levels with diffuse coronary artery disease in patients with type 2 diabetes mellitus. Clin Chim Acta 2009; 408: 45-9.

15. Fang SC, Eisen EA, Cavallari JM, Mittleman MA, Christiani DC. Circulating adhesion molecules after short-term exposure to particulate matter among welders. Occup Environ Med 2010; 67: 11-6.

16. Michael Pittilo R. Cigarette smoking, endothelial injury and cardiovascular disease. In J Exp Pathol 2000; 81: 21930.

17. Orea Soler I, Illán Gómez F, Gonzálvez Ortega M, et al. Soluble intercellular adhesion molecule- 1 and $C$ reactive protein after bariatric surgery. Endocrinol Nutr 2010; 57 : 90-4. 